\title{
Enhanced International Prognostic Index (NCCN-IPI), Charlson Comorbidity Index and absolute lymphocyte count as predictors for survival of elderly patients with diffuse large B cell lymphoma treated by immunochemotherapy
}

\author{
J. JELICIC ${ }^{1,2}$, M. TODOROVIC BALINT ${ }^{1,2, *}$, D. ANTIC ${ }^{1,2}$, A. SRETENOVIC ${ }^{1}$, B. BALINT ${ }^{3}$, M. PERUNICIC JOVANOVIC ${ }^{4}$, B. ANDJELIC ${ }^{1,2}$, V. VUKOVIC ${ }^{1}$, \\ V. DJURASINOVIC ${ }^{1}$, J. BILA ${ }^{1,2}$, M. PAVLOVIC ${ }^{5}$, M. SMILJANIC ${ }^{1}$, B. MIHALJEVIC ${ }^{1,2}$ \\ ${ }^{1}$ Clinic of Hematology, Clinical Center of Serbia; ${ }^{2}$ Faculty of Medicine, University of Belgrade, Serbia; ${ }^{3}$ Institute for Transfusiology and Hemobi- \\ ology MMA Belgrade, Serbia; ${ }^{4}$ Department of Histopathology, Clinical Center of Serbia; ${ }^{5}$ Department of Computer and Electrical Engineering \\ and Computer Science, FAU, FL,USA
}

${ }^{*}$ Correspondence: bb.lena@gmail.com

Received May 21, 2015 / Accepted July 22, 2015

\begin{abstract}
Diffuse large B cell lymphoma (DLBCL) affects more commonly patients over 60 years. These patients have vast number of comorbidities which can modify survival as well as other clinical parameters. The aim of this study was to evaluate prognostic significance of the National Comprehensive Cancer Network International Prognostic Index (NCCN-IPI), absolute lymphocyte count (ALC), absolute monocyte count (AMC), lymphocyte-to-monocyte ratio (LMR) and comorbidities expressed with Charlson Comorbidity Index (CCI).

A total of 182 DLBCL patients 60 years old and older were included, focusing on whole group and patients older than 70. All patients were treated with immunochemotherapy. Overall treatment response was achieved in $84.6 \%$ of patients. The NCCN-IPI was of highly prognostic value in the analyzed group $(\mathrm{p}<0.0001)$. Survival analysis showed that ALC $>1.1 \times 10^{9} / \mathrm{L}$, $\mathrm{AMC} \leq 0.59 \times 10^{9} / \mathrm{L}$, and $\mathrm{LMR}>2.8$ were associated with more favorable outcome $(\mathrm{p}=0.029, \mathrm{p}=0.019, \mathrm{p}=0.028$, respectively). The patients with $\mathrm{CCI} \geq 2$ had poorer outcome $(\mathrm{p}=0.008)$ compared to the patients with CCI 0 - 1 . Multivariate analysis showed that among ALC, AMC, LMR, NCCN-IPI and CCI, the NCCN-IPI was the critical parameter that significantly affected survival $(\mathrm{p}<0.0001)$. Furthermore, comorbidities were also valuable independent factors which influenced survival $(\mathrm{p}=0.031)$ as well as the ALC ( $\mathrm{p}=0.024)$. In elderly DLBCL patients, NCCN-IPI and ALC proved their prognostic validity, while poorer outcome could be expected in older patients with high CCI $(\geq 2)$. Furthermore, mentioned prognostic parameters retained their prognostic value in the group of patients older than 70 .
\end{abstract}

Key words: DLBCL, Charlson comorbidity index, absolute lymphocyte count, NCCN-IPI

Diffuse large B cell lymphoma (DLBCL) is the most common type of non-Hodgkin lymphoma with the majority of patients/individuals older than 60 years [1]. Older age represents an adverse prognostic factor with poorer outcome in DLBCL patients older than 70 years (34\%) comparing to patients aged 60-69 years (51\%) [2]. The incidence of DLBCL in elderly patients is progressively rising [3]. The addition of rituximab to standard chemotherapy has significantly extended survival of patients with DLBCL $[4,5]$. However, the treatment of elderly patients requires consideration of additional factors such as potential functional decline with age (reduction of glomerular filtration rate, reduced muscle mass, decreased liver clearance, reduced hematological reserve), comorbidities and performance status (PS) [6,7]. Due to the age-bias, elderly patients are mostly not selected to enter clinical studies because of higher incidence of deaths not related to lymphoma [3]. The complete remission (CR) rates are lower in the elderly patients, and one of the reasons may be suboptimal treatment [3]. However, a number of factors are associated with treatment and make treatment decision more complicated.

In order to stratify risk categories, the International Prognostic Index (IPI) has been used during the past two decades [7]. However, the value of the IPI has been reported to decline 
in the rituximab era and revised prognostic scores have been developed [7-9]. Recently, an enhanced IPI (NCCN-IPI) from the National Comprehensive Cancer Network database has been developed, based on five parameters (age, lactate dehydrogenase (LDH), sites of involvement, Ann Arbor stage, Eastern Cooperative Oncology Group (ECOG) PS) with the progression of the age and the LDH level [10]. This index better discriminate low and high-risk subgroups compared with the IPI, but need to be evaluated in different populations of patients [10].

Recent research studies have focused on a correlation between immune microenvironment and lymphoma biology. As the result, absolute lymphocyte count (ALC), absolute monocyte count (AMC), derived from pre-treatment cell blood counts $(\mathrm{CBC})$, and lymphocyte-to-monocyte ratio (LMR) were tested. These surrogate biomarkers of the immune microenvironment, showed to be the efficient prognostic parameters in DLBCL patients treated with R-CHOP therapy (rituximab, cyclophosphamide, doxorubicin, vincristine, and prednisolone) [11-15]. However, none of these studies have focused on the elderly population.

Comorbidities, the life-shortening diseases that were present at the time of the malignant disorder diagnosis, can be categorized using different Comorbidity scales [16-18]. Charlson Comorbidity Index (CCI) was developed by Mary Charlson in 1987 and since then has been widely used for calculating comorbidity score in cancer patients. More than $70 \%$ of the patients with aggressive NHL older than 60 years have at least one comorbidity state at presentation including hypertension (22\%), heart and vascular diseases (19\%) and previously diagnosed malignancies $(15 \%)[3,19]$. The recent studies which have investigated the influence of comorbidities on the outcome of DLBCL patients, have suggested that DLBCL patients with high CCI have lower overall response rate, higher therapy related toxicity and an increased rate of lethal outcome [3, 16-18].

This study aimed to investigate the impact of the AMC, ALC, LMR, NCCN-IPI and comorbidities on the overall survival of patients who were at the time of diagnosis 60 years and older and were treated with rituximab plus $\mathrm{CHOP}$ based combinations.

\section{Patients and methods}

We have retrospectively analyzed data from a total of 182 DLBCL patients who were 60 years and older, diagnosed and treated between January 2005 and December 2013 at our Institution [20]. Among them 79 patients (43\%) were more than 70 years old. Regarding clinical characteristics, about 97 patients (53.3\%) had advanced stage of disease (Ann Arbor III-IV). Constitutional B symptoms were present in 61 patients (33.5\%) while bulky disease in 41 (22.5\%). The extranodal localization of lymphoma was registered in 106 patients (58.2\%). The bone marrow infiltration had 34/182 patients (18.7\%). According to the NCCN-IPI the distribution was as following: low risk was present in 6 patients (3.3\%), low intermediate in $78(42.9 \%)$, high intermediate in $73 \%(40.1 \%)$ and high risk in 25 (13.7\%). Regarding albumin level, 108 patients (59.3\%) had normal level, below lower limit normal (LLN) had 51 patients (28\%) and for 23 patients (12.6\%) data were not applicable. Regarding CCI, one comorbidity was present in $83 / 182$ patients (45.6\%) while $27 / 182$ patients ( $14.8 \%$ ) had high CCI $\geq 2$ (Table 1). All patients received immunochemotherapy including 164 patients (90.1\%) who were treated with R-CHOP and 18 patients (9.9\%) with R-CVP (rituximab, cyclophosphamide, vincristine, and prednisolone). This study was approved by the Ethical Committee of the Faculty of Medicine, University of Belgrade, Serbia.

\section{Statistical analyzes}

Using the approach of Kaplan and Meier, overall survival (OS) and event-free survival (EFS) were analyzed [21]. Differences between survival curves were tested using the two-tailed Log Rank test. OS was calculated as the time of diagnosis

Table 1. Clinical characteristics of 182 patients with diffuse large B cell lymphoma

\begin{tabular}{ll}
\hline Age median (range) & $68.4(60-80$ years) \\
\hline Gender (male/female) & Number of patients (\%) \\
\hline Ann Arbor stage & \\
I-II & $85(46.7 \%)$ \\
III-IV & $97(53.3 \%)$ \\
\hline ECOG PS & \\
$0-1$ & $144(79.1 \%)$ \\
$\geq 2$ & $38(20.9 \%)$ \\
\hline B symptoms & $61(33.5 \%)$ \\
\hline Bulky disease & $41(22.5 \%)$ \\
\hline Extranodal disease & $106(58.2 \%)$ \\
\hline Bone marrow infiltration & $34(18.7 \%)$ \\
\hline NCCN-IPI & \\
Low & $6(3.3 \%)$ \\
Low-intermediate & $79(42.9 \%)$ \\
High-intermediate & $73(40.1 \%)$ \\
High & $25(13.7 \%)$ \\
\hline ALC $>1.1 \times 10^{9} / L$ & $128(70.3 \%)$ \\
ALC $\leq 1.1 \times 10^{9} / \mathrm{L}$ & $54(29.7 \%)$ \\
AMC $\leq 0.59 x 10^{9} / \mathrm{L}$ & $123(67.6 \%)$ \\
AMC $>0.59 x 10^{9} / \mathrm{L}$ & $59(32.4 \%)$ \\
LMR $>2.8$ & $109(59.9 \%)$ \\
LMR $\leq 2.8$ & $73(40.1 \%)$ \\
\hline Albumin $<$ LLN & $51(28 \%)$ \\
\hline CCI $0-1$ & $155(85.2 \%)$ \\
CCI $\geq 2$ & $27(14.8 \%)$ \\
\hline
\end{tabular}

Eastern Cooperative Oncology Group performance status (ECOG PS), Absolute lymphocyte count (ALC), Absolute monocyte count (AMC), Lymphocyte to monocyte ratio (LMR), Lower limit normal (LLN), Charlson Comorbidity Index (CCI) 




Figure 1. Receiver Operating Curve (ROC) analysis: optimal cut-off value in predicting survival for ALC.

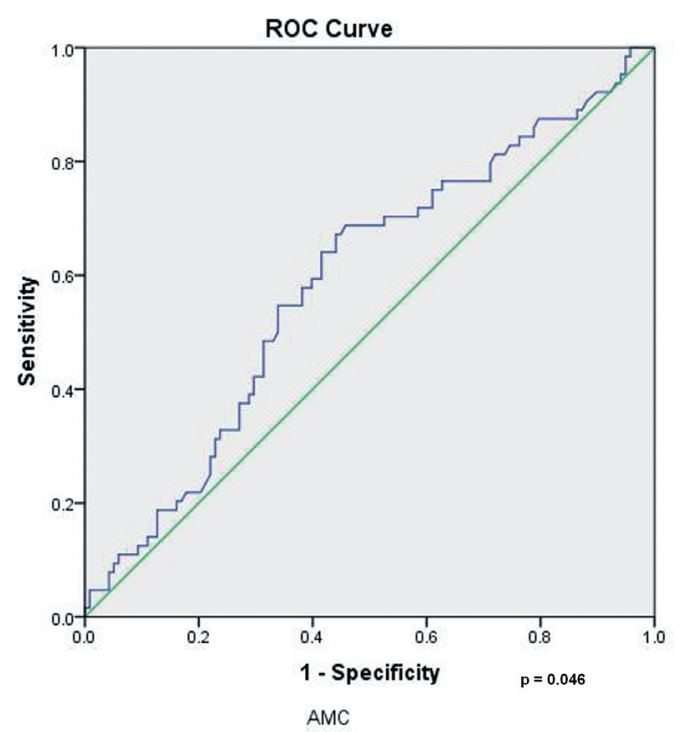

Figure 2. Receiver Operating Curve (ROC) analysis: optimal cut-off value in predicting survival for AMC.

until the last follow up point for alive patients (January 2015) or until lethal outcome. EFS was calculate as the time from diagnosis until the last follow up point for event (relapse) for alive patients (January 2015) or death. The treatment response was evaluated according to the previously reported response criteria [22]. In order to determine relationships between categorical variables Chi square test was used. The Receiver Operating Curve (ROC) method was used in order to determine optimal cut-off value for the ALC, AMC and LMR. The Cox's regression method was performed to examine the effect of parameters which had shown the prognostic impact on

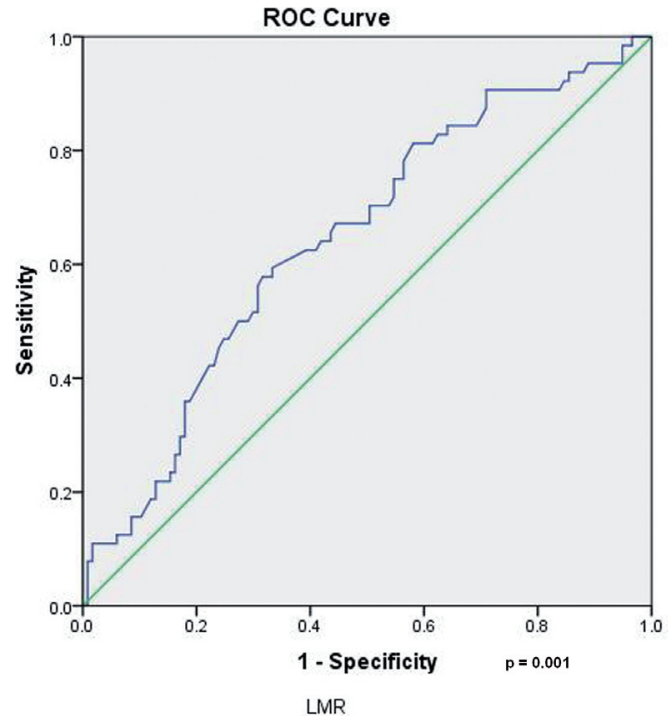

Figure 3. Receiver Operating Curve (ROC) analysis: optimal cut-off value in predicting survival for LMR.

the EFS and OS in univariate analysis [23]. All statistical tests were two-sided, with $p$ value $\leq 0.05$ regarded as significant. All statistical analyses were performed in SPSS program version 21 software (IBM SPSS).

\section{Results}

A total of 182 patients (72 males/110 females) had the median age at diagnosis 68.4 years (range of 60-80 years). At diagnosis median ALC was $1.54 \times 10^{9} / \mathrm{L}$ (range 0.116 $14.820 \times 10^{9} / \mathrm{L}$ ), AMC $0.49 \times 10^{9} / \mathrm{L}$ (range $0.058-8.58 \times 10^{9} / \mathrm{L}$ ) and LMR 3.2 (range 0.270-20.670). The ROC curves were used in order to select the cutoff points of ALC, AMC, and LMR for survival outcomes. The most discriminative cut off value for ALC was $1.10 \times 10^{9} / \mathrm{L}$, with an area under the curve (AUC) value of 0.594 (95\% CI, 0.509-0.680, p=0.036) (Figure 1). ALC $>1.1 \times 10^{9} / \mathrm{L}$ had 128 patients (70.3\%). The most discriminative cutoff value for AMC was $0.59 \times 10^{9} / \mathrm{L}$, with an AUC value of 0.59 (95\% CI, 0.503-0.676, $\mathrm{p}=0.046$ ) (Figure 2). AMC $\leq 0.59 \times 10^{9} / \mathrm{L}$ had 123 patients (67.6\%). The most discriminative cut-off for LMR was 2.8, with an AUC value of 0.645 (95\%CI, 0.562-0.728, p=0.001) (Figure 3). LMR $<2.8$ was registered in 109 patients (59.9\%). High CCI $\geq 2$ was registered in 27 patients $(14.8 \%)$.

Overall treatment response (CR and partial remission PR) were achieved in 154 patients (84.6\%) and 28 patients (15.4\%) had primary resistant disease. CR was achieved in $126 / 154$ patients $(81.8 \%)$ and PR in 28 (18.2\%) (Table 2). The overall treatment response was achieved in 114 patients (89.1\%) with ALC $>1.1 \times 10^{9} / \mathrm{L}$ comparing to 41 patients (75.9\%) with $\mathrm{ALC} \leq 1.1 \times 10^{9} / \mathrm{L}(\mathrm{p}=0.029)$. CR and PR were achieved in 110 patients (89.4\%) with $\mathrm{AMC} \leq 0.59 \times 10^{9} / \mathrm{L}$ and in 45 patients $(76.3 \%)$ with $\mathrm{AMC}>0.59 \times 10^{9} / \mathrm{L}(\mathrm{p}=0.019)$. 


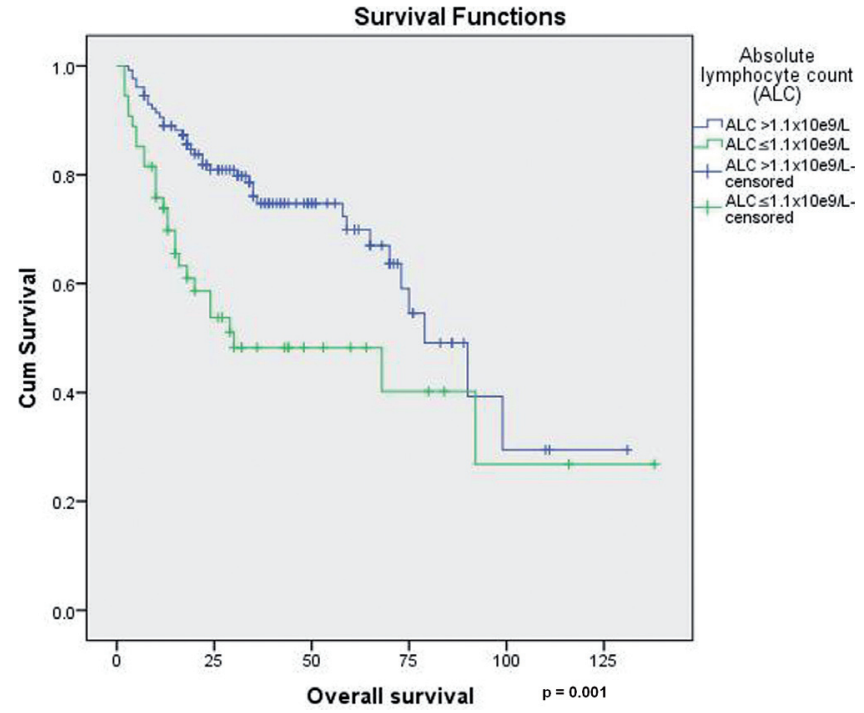

Figure 4. Overall survival curve of DLBCL patients according to ALC value.

Regarding LMR, treatment response has been noticed in 98 patients $(89.9 \%)$ with LMR $>2.8$ and 57 patients $(78.1 \%)$ with LMR $\leq 2.8$ ( $\mathrm{p}=0.028)$. According to the NCCN-IPI, CR and PR were achieved in 6 patients (100\%), 74 (94.9\%), 59 (80.8\%) and $16(64.0 \%)$ in low, low intermediate, high intermediate and high risk group, respectively $(\mathrm{p}<0.0001)$. Furthermore, patients with normal albumin level had superior therapeutic response (97 patients, $89.8 \%$ ) comparing to the patients with low albumin level ( 40 patients, $78.4 \%, \mathrm{p}=0.05$ ). Patients with high $\mathrm{CCI} \geq 2$ had inferior outcome (19 patients, $70.4 \%$ ) comparing to the patients with CCI $0-1$ (136 patients, $87.7 \%$, $\mathrm{p}=0.035$ ).

The disease relapse was verified in $39 / 182$ patients (24.9\%) and primary resistant disease existed in 28 patients (15.4\%). Adverse parameters including ALC $\leq 1.1 \times 10^{\%} / \mathrm{L}$, $\mathrm{AMC}>0.59 \times 10^{9} / \mathrm{L}, \mathrm{LMR} \leq 2.8$, and NCCN-IPI $\geq 4$ were associated with higher relapse rate $(p=0.008, p=0.036, p=0.005$, $\mathrm{p}<0.0001$, respectively) (Table 2 ).

There were no differences in survival according to the gender ( $\log \operatorname{Rank}=0.093, \mathrm{p}=0.76)$, presence of $\mathrm{B}$ symptoms ( $\log R a n k=1.432, \mathrm{p}=0.23$ ) nor bulky disease ( $\log$ Rank $=0.054, \mathrm{p}=0.82$ ). The Kaplan-Meier analysis showed that $\mathrm{ALC}>1.1 \times 10^{9} / \mathrm{L}$ at diagnosis was associated with superior EFS (Log Rank=11.08, $\mathrm{p}=0.001)$ and OS (Log Rank=10.103, $\mathrm{p}=0.001$ ) comparing to ALC $\leq 1.1 \times 10^{9} / \mathrm{L}$ (Figure 4). Patients with $\mathrm{AMC}>0.59 \times 10^{9} / \mathrm{L}$ had adverse EFS (Log Rank $=8.31$, $\mathrm{p}=0.004)$ and $O S(\log \operatorname{Rank}=8.57, \mathrm{p}=0.003)$ compared with the patients with $\mathrm{AMC} \geq 0.59 \times 10^{9} / \mathrm{L}$ (Figure 5). Furthermore, LMR $>2.8$ was associated with favorable EFS ( $\log$ Rank $=12.21$, $\mathrm{p}<0.001)$ and $\mathrm{OS}(\log \mathrm{Rank}=11.75, \mathrm{p}=0.001)$ (Figure 6).

The NCCN-IPI was able to distinguish patients with high, and high-intermediate risk who had significantly lower EFS (Log Rank=40.12, p <0.0001) and OS (Log Rank=41.37,

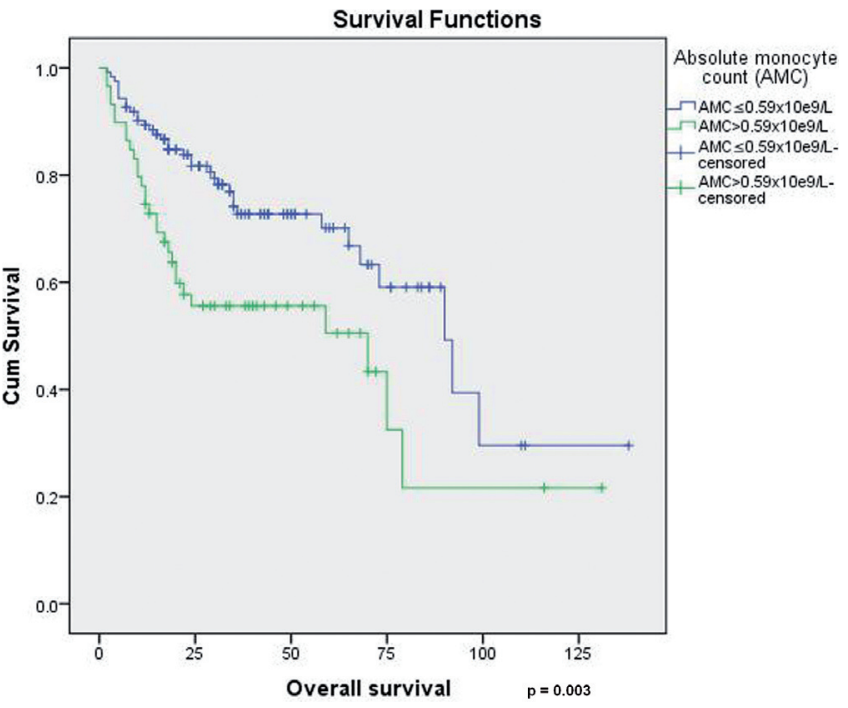

Figure 5. Overall survival curve of DLBCL patients according to AMC value.

$\mathrm{p}<0.0001)$ as compared to low risk group. The low albumin level was associated with lower EFS (Log Rank 4.11, p=0.043) while it had borderline significance on the OS ( $\log$ Rank $=3.63$, $\mathrm{p}=0.057)$. The patients with high comorbidity score $(\mathrm{CCI} \geq 2)$ had poorer EFS (Log Rank=6.88, $\mathrm{p}=0.009)$ and OS ( $\log$ Rank=6.97, $\mathrm{p}=0.008$ ) compared to the patients with low CCI (Figure 7).

Table 2. Overall treatment response (CR, PR) and relapse rate according to the ALC, AMC, LMR, NCCN-IPI and CCI

\begin{tabular}{lccc}
\hline & No of pts (\%) & p value & $\begin{array}{c}\text { Correlation with } \\
\text { relapse rate }\end{array}$ \\
\hline CR & $126 / 154(81.8 \%)$ & \\
\hline PR & $28 / 154(18.2 \%)$ & & \\
\hline Relapsed disease & $39 / 182(24.9 \%)$ & & \\
\hline Resistant disease & $28 / 182(15.4 \%)$ & \\
\hline NCCN-IPI & & & \\
Low & $6(100 \%)$ & $\mathrm{p}<0.0001$ & \\
Low-intermediate & $74(94.9 \%)$ & & \\
High-intermediate & $59(80.8 \%)$ & & \\
High & $16(64.0 \%)$ & & \\
\hline ALC $>1.1 \times 10^{9} / \mathrm{L}$ & $114(89.1 \%)$ & $\mathrm{p}=0.029$ \\
ALC $\leq 1.1 \times 10^{9} / \mathrm{L}$ & $41(75.9 \%)$ & & $\mathrm{p}=0.036$ \\
\hline AMC $\leq 0.59 \times 10^{9} / \mathrm{L}$ & $110(89.4 \%)$ & $\mathrm{p}=0.019$ \\
AMC $>0.59 \times 10^{9} / \mathrm{L}$ & $45(76.3 \%)$ & & $\mathrm{p}=0.005$ \\
\hline LMR $>2.8$ & $89(89.9 \%)$ & $\mathrm{p}=0.028$ & $\mathrm{p}>0.05$ \\
\hline LMR $\leq 2.8$ & $57(78.1 \%)$ & & $\mathrm{p}=0.039$ \\
\hline CCI $0-1$ & $136(87.7 \%)$ & & \\
CCI $\geq 2$ & $19(70.4 \%)$ & & \\
\hline
\end{tabular}

Complete remission (CR), Partial remission (PR), Absolute lymphocyte count (ALC), Absolute monocyte count (AMC), Lymphocyte to monocyte ratio (LMR), Lower limit norm al (LLN), Charlson Comorbidity Index (CCI) 


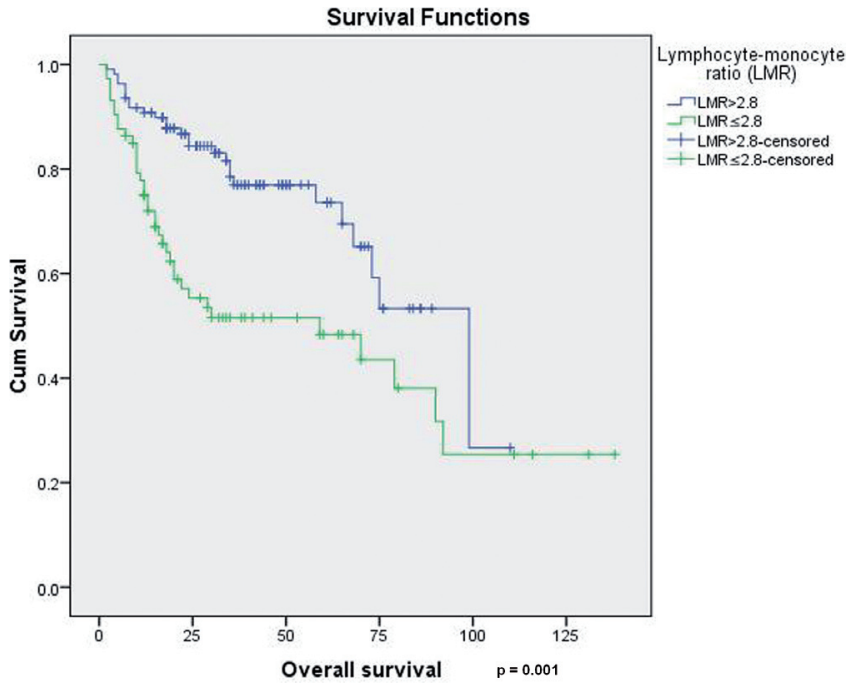

Figure 6. Overall survival curve of DLBCL patients according to LMR value.

Multivariate Cox regression analysis was used to evaluate the prognostic significance of the following parameters: ALC, AMC, LMR, NCCN-IPI and CCI on the EFS and OS. The results have shown highly significant test model $(\mathrm{p}<0.0001)$ with NCCN-IPI as the most important independent parameter which affected survival - EFS (HR 1.58, 95 CI, 1.316-1.889, $\mathrm{p}<0.0001)$ and OS (HR 1.63, 95\% CI, 1.357-1.950, $\mathrm{p}<0.0001$ ). Comorbidities were also an independent prognostic factor for EFS (HR 0.54, 95\% CI, 0.294-0.976, $\mathrm{p}=0.041$ ) and OS (HR $0.516,95 \%$ CI, $0.282-0.942, p=0.031$ ). Furthermore, the ALC was identified as the parameter with significant impact on the EFS (HR 0.559, 95\% CI, 0.321-0.974, $\mathrm{p}=0.04$ ) and OS (HR $0.525,95 \%$ CI, 0.300-0.919, $\mathrm{p}=0.024$ ) (Table 3). All examined parameters were tested equally in the whole group of patients, and in the particular group of 79 patients older than 70 years, and they retained their statistical significance for therapeutic outcome and survival (ALC $p=0.001$, NCCN-IPI $p=0.011$, CCI $\mathrm{p}=0.013)$. Regarding OS in the context of gender, tested parameters in Kaplan Mayer analysis were still valid in both

Table 3. Multivariate analysis (Cox regression model) of prognostic factors for overall survival

\begin{tabular}{lcccc}
\hline & & & \multicolumn{2}{c}{$95.0 \%$ CI } \\
\cline { 4 - 5 } & P value & HR & Lower & Upper \\
\hline ALC & 0.024 & 0.525 & 0.300 & 0.919 \\
AMC & 0.143 & 0.628 & 0.337 & 1.171 \\
LMR & 0.348 & 0.732 & 0.381 & 1.406 \\
NCCN-IPI & 0.000 & 1.627 & 1.357 & 1.950 \\
CCI & 0.031 & 0.516 & 0.282 & 0.942 \\
\hline
\end{tabular}

Absolute lymphocyte count (ALC), Absolute monocyte count (AMC), Lymphocyte to monocyte ratio (LMR), Charlson Comorbidity Index (CCI).

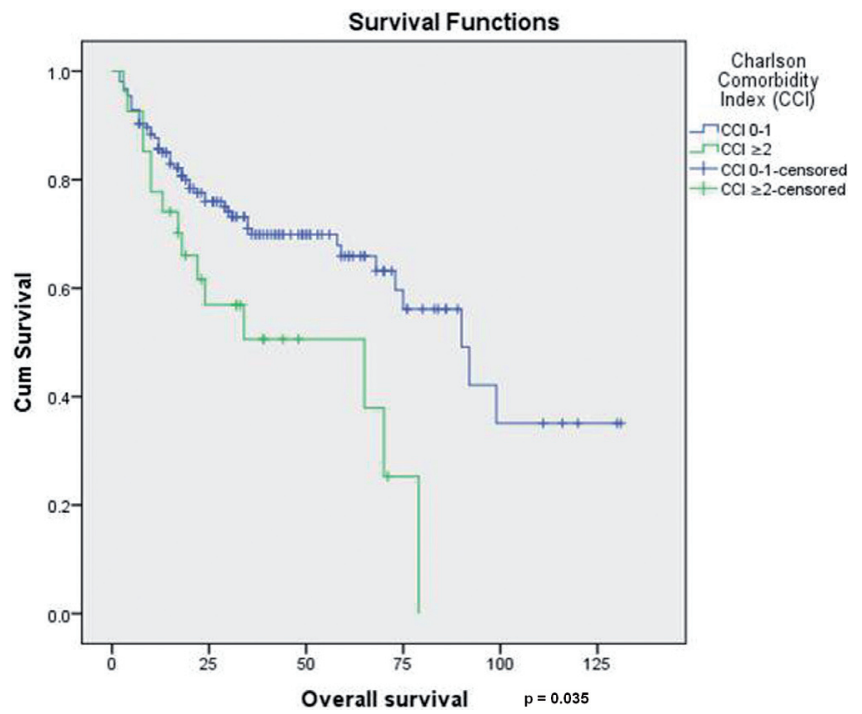

Figure 7. Overall survival curve of 184 lymphoma patients according to the Charlson Comorbitity Index (CCI).

male and female patients (ALC $\mathrm{p}=0.001, \mathrm{AMC} \mathrm{p}=0.003$, LMR $\mathrm{p}=0.039$, NCCN-IPI $\mathrm{p}=0.001$, CCI $\mathrm{p}=0.006$ ).

Comparing therapeutic effectiveness of R-CHOP (61 patients) vs. R-CVP (18 patients), there were no statistical differences in patients older than 70 years ( $\log \operatorname{Rank}=2.25$, $\mathrm{p}=0.133$ ), since antracyclin free regimen was applied due to comorbid conditions.

\section{Discussion}

In the era of novel achievements in the field of molecular genetics using very advanced techniques such as gene expression profiling (GEP), whole genome sequencing and next generation sequencing analyses (mostly unavailable in majority of hospitals and their laboratories), the importance of attainable clinical parameters is sometimes neglected. We have tried, using easy clinical tools, to evaluate the impact of clinical parameters on the survival of elderly patients with DLBCL treated with immunochemotherpy.

Since the introduction of rituximab, the outcome of the patients with DLBCL has been significantly improved which was demonstrated also in the elderly population with DLBCL $[4,5,24]$. For the last two decades, the IPI was keystone for initial differentiation of risk categories in DLBCL patients. Developed in the pre-rituximab era, the IPI lost its power to discriminate four risk categories of patients in the rituximab era [8-10]. Since the value of the IPI has declined with the addition of rituximab, there have been made attempts in order to enhance the value of IPI designing new scoring algorithms. Recently, there has been developed the NCCN-IPI which is based on a similar set of parameters included in the IPI for recognition 4 risk groups but with refined categorization for age and level of LDH [10]. In order to further improve the 
value of NCCN-IPI in elderly population, the addition of albumin and $\beta 2$ microglobulin were tested and proved to have prognostic significance [25].

It is well known that the tumor microenvironment plays very important role in lymphomagenesis [26, 27]. Based on GEP studies it has been shown that gene expression by tumorinfiltrating lymphocytes and myeloid-derived cells can be used to predict clinical outcome [26]. These results were starting point in analyzing the prognostic significance of peripheral blood lymphocyte and monocyte counts as the biomarkers of immune microenvironment. Tadmor et al. suggested the prognostic value of AMC alone, even when adjusted for IPI [11]. Few other studies have suggested the prognostic impact of ALC, AMC and LMR on the OS of patients with DLBCL treated with rituximab plus $\mathrm{CHOP}$ or $\mathrm{CHOP}$ like regiments [11-15]. Prognostic significance of ALC at diagnosis of DLBCL was confirmed in few studies as well as in a meta-analysis published by Feng et al. based on six previously published studies [12]. On contrary, Plonquet et al. tested a group of younger DLBCL patients, and reported an association between circulating NK cell number and clinical outcome in DLBCL. However, they haven 't marked ALC as a parameter that influenced outcome [28]. The significance of AMC on survival of DLBCL patients was confirmed in few studies and became an important factor in developing and testing LMR. Furthermore, these studies confirmed the prognostic significance of ALC, AMC, LMR, absolute monocyte and lymphocyte prognostic score as the independent predictors of progression-free survival and OS [11-15]. However, all these studies were performed on the general DLBCL population neglecting some characteristics of the elderly population that modify treatment tolerance and outcome [3]. Our study confirmed the prognostic impact of ALC, AMC and LMR as individual parameters. But, when they were adjusted with other parameters (CCI and NCCN-IPI), only ALC retained its prognostic significance.

Since age has been considered as negative prognostic factor, different prognostic scores have been evaluated in the elderly population [29-32]. The old population suffers from eminent number of co morbid conditions that are present at the time of diagnosis of lymphoma. More than $70 \%$ of patients over the age of 60 with the diagnosis of aggressive NHL have some comorbid condition according to the Eindhoven Cancer Registry [33]. Our study population had lower comorbidity rate which could be due to the undiagnosed comorbid conditions. The different comorbidity scales are available in order to estimate comorbid conditions [1618, 32]. Unfortunately, high comorbidity score sometimes leads to suboptimal treatment of these patients [3]. Using CCI, the impact of comorbid conditions on the PFS and OS of elderly patients with DLBCL has been evaluated. Few studies have shown significantly poorer outcome of the patients with high $\mathrm{CCI} \geq 2$, as well as lower overall response rate and higher therapy related toxicity when treated with standard R-CHOP protocol [34-36]. The poorer outcome of these patients may also be due to the comorbidity itself or the lower threshold for treatment dose reduction [3].
Our results confirmed that the NCCN-IPI was precise tool to stratify prognostically relevant subgroups of DLBCL patients over 60 years. Comorbidities in elderly patients are independently associated with poorer outcome and should be specifically evaluated at presentation in order of giving the most appropriate therapy. However, the multivariate analyses of our data showed the importance of ALC on the outcome of elderly patients with DLBCL.

\section{Conclusion}

In elderly patients with DLBCL, prognostic index such as NCCN-IPI proved its validity, while ALC can be exploited for risk stratification at diagnosis. Finally, poorer outcome can be expected in older patients with high CCI $(\geq 2)$.

Acknowledgements: This work was supported by Ministry of Science Project No 41004.

\section{References}

[1] EKSTROM-SMEDBY K. Epidemiology and etiology of nonHodgkin lymphoma - a review. Acta Oncol. 2006; 45: 258-271. http://dx.doi.org/10.1080/02841860500531682

[2] LINK BK, BROOKS J, WRIGHT K, PAN X, VOELKER M, et al. Diffuse large B-cell lymphoma in the elderly: diffusion of treatment with rituximab and survival advances with and without anthracyclines. Leuk Lymphoma. 2011; 52: 994-1002. http://dx.doi.org/10.3109/10428194.2011.5 $\underline{57167}$

[3] FIELDS PA, LINCH DC. Treatment of the elderly patient with diffuse large B cell lymphoma. Br J Haematol. 2012; 157: 159170. http://dx.doi.org/10.1111/j.1365-2141.2011.09011.x

[4] COIFFIER B, LEPAGE E, BRIERE J, HERBRECHT R, TILLY $\mathrm{H}$, et al. $\mathrm{CHOP}$ chemotherapy plus rituximab compared with CHOP alone in elderly patients with diffuse large-B-cell lymphoma. N Engl J Med. 2002; 346: 235-242. http://dx.doi. org/10.1056/NEJMoa011795

[5] HABERMANN TM, WELLER EA, MORRISON VA, GASCOYNE RD, et al. Rituximab-CHOP versus CHOP alone or with maintenance rituximab in older patients with diffuse large B-cell lymphoma. J Clin Oncol. 2006; 24: 3121-3127. http://dx.doi.org/10.1200//CO.2005.05.1003

[6] NASTOUPIL LJ, SINHA R, FLOWERS CR. Management strategies for elderly patients with diffuse large B-cell lymphoma. Eur Oncol Haematol. 2012; 9: 123-126.

[7] The International Non-Hodgkin's Lymphoma Prognostic Factors Project. A predictive model for aggressive non Hodgkin's lymphoma. N EnglJMed.1993: 329: 987-994. http://dx.doi. org/10.1056/NEJM199309303291402

[8] SEHN LH, BERRY B, CHHANABHAI M, FITZGERALD C, GILL K, et al. The revised International Prognostic Index (R-IPI) is a better predictor of outcome than the standard IPI for patients with diffuse large B-cell lymphoma treated with R-CHOP. Blood. 2007; 109: 1857-1861. http://dx.doi. org/10.1182/blood-2006-08-038257 
[9] ZIEPERT M, HASENCLEVER D, KUHNT E, GLASS B, SCHMITZ N, et al. Standard International prognostic index remains a valid predictor of outcome for patients with aggressive CD20+ B-cell lymphoma in the rituximab era. J Clin Oncol. 2010; 28: 2373-2380. http://dx.doi.org/10.1200/ LCO.2009.26.2493

[10] ZHOU Z, SEHN LH, RADEMAKER AW, GORDON LI, LACASCE AS, et al. An enhanced International Prognostic Index (NCCN-IPI) for patients with diffuse large B-cell lymphoma treated in the rituximab era. Blood. 2014; 123: 837-842. http://dx.doi.org/10.1182/blood-2013-09-524108

[11] TADMOR T, BARI A, SACCHI S, MARCHESELLI L, LIARDO EV, et al. Monocyte count at diagnosis is a prognostic parameter in diffuse large B-cell lymphoma: results from a large multicenter study involving 1191 patients in the preand post-rituximab era. Haematologica. 2014; 99: 125-130. http://dx.doi.org/10.3324/haematol.2013.088161

[12] FENG J, WANG Z, GUO X, CHEN Y, CHENG Y, et al. Prognostic significance of absolute lymphocyte count at diagnosis of diffuse large B-cell lymphoma: a meta-analysis. Int J Hematol 2012; 95: 143-148. http://dx.doi.org/10.1007/ $\underline{\text { s12185-011-0993-6 }}$

[13] WILCOX RA, RISTOW K, HABERMANNTM, INWARDS DJ, MICALLEF IN, et al. The absolute monocyte and lymphocyte prognostic score predicts survival and identifies high-risk patients in diffuse largeB-cell lymphoma. Leukemia 2011; 25: 1502-1509. http://dx.doi.org/10.1038/leu.2011.112

[14] AOKI K, TABATA S, YONETANI N, MATSUSHITA A, ISHIKAWA T. The prognostic impact of absolute lymphocyte and monocyte counts at diagnosis of diffuse large B-cell lymphoma in the rituximab era. Acta Haematol. 2013; 130: 242-246. http://dx.doi.org/10.1159/000350484

[15] MARKOVIC O, POPOVIC L, MARISAVLJEVIC D, JOVANOVIC D, FILIPOVIC B, et al. Comparison of prognostic impact of absolute lymphocyte count, absolute monocyte count, absolute lymphocyte count/absolute monocyte count prognostic score and ratio in patients with diffuse large B cell lymphoma. Eur J Intern Med. 2014; 25: 296-302. http://dx.doi. org/10.1016/j.ejim.2014.01.019

[16] CHARLSON ME, POMPEI P, ALES KL, MACKENZIE CR. A new method of classifying prognostic comorbidity in longitudinal studies: development and validation. J Chronic Dis. 1987; 40: 373-383. http://dx.doi.org/10.1016/0021-9681(87) $90171-8$

[17] PICCIRILLO JF, TIERNEY RM, COSTAS I, GROVE L, SPITZNAGEL EL JR. Prognostic importance of comorbidity in a hospital-based cancer registry. JAMA. 2004; 291: 2441-2447. http://dx.doi.org/10.1001/jama.291.20.2441

[18] SORROR ML, MARIS MB, STORB R, BARON F, SANDMAIER BM, et al. Hematopoietic cell transplantation (HCT)-specific comorbidity index: a new tool for risk assessment before allogeneic HCT. Blood. 2005; 106: 2912-2919. http://dx.doi.org/10.1182/blood-2005-05-2004

[19] HAINSWORTH JD, FLINN IW, SPIGEL DR, CLARK BL, GRINER PL, et al. Brief-duration rituximab/chemotherapy followed by maintenance rituximab in patients with diffuse large B-cell lymphoma who are poor candidates for R-CHOP chemotherapy: a phase II trial of the Sarah Cannon Oncology Research Consortium. Clin Lymphoma Myeloma Leuk. 2010; 10: 44-50. http://dx.doi.org/10.3816/CLML.2010.n.004

[20] JAFFE S. The 2008 WHO classification of lymphomas: implications for clinical practice and translational research. Hematology Am Soc Hematol Educ Program. 2009: 523-31.

[21] KAPLAN E, MEIER P. Nonparametric estimation from incomplete observations. J Am Stat Assoc. 1958; 53: 457-481. http://dx.doi.org/10.1080/01621459.1958.10501452

[22] CHESON BD, PFISTNER B, JUWEID ME, GASCOYNE $\mathrm{RD}, \mathrm{SPECHT}$ L, et al. Revised response criteria for malignant lymphoma. J Clin Oncol. 2007; 25: 579-586. http://dx.doi. org/10.1200/JCO.2006.09.2403

[23] COX DR. Regression models and life-tables. J R Stat Soc (B). 1972; 34: 187-202.

[24] COIFFIER B, LEPAGE E, BRIERE J, HERBRECHT R, TILLY $\mathrm{H}$, et al. CHOP chemotherapy plus rituximab compared with CHOP alone in elderly patients with diffuse large-B-cell lymphoma. N Engl J Med. 2002; 346: 235-242. http://dx.doi. org/10.1056/NEJMoa011795

[25] MELCHARDT T, TROPPAN K, WEISS L, HUFNAGL C, NEUREITER D, et al. A modified scoring of the NCCN-IPI is more accurate in the elderly and is improved by albumin and $\beta 2$-microglobulin. Br J Haematol. 2015; 168: 239-245. http://dx.doi.org/10.1111/bjh.13116

[26] LENZ G, WRIGHT G, DAVE SS, XIAO W, POWELL J, et al. Lymphoma/Leukemia Molecular Profiling Project. Stromal gene signature in large B cell lymphomas. N Engl J Med 2008; 22: 2313-2323. http://dx.doi.org/10.1056/NEJMoa0802885

[27] TRAN H, NOURSE J, HALL S, GREEN M, GRIFFITHS L, et al. Immunodeficiency associated lymphomas. Blood Rev. 2008; 22: 261-281. http://dx.doi.org/10.1016/j.blre.2008.03.009

[28] PLONQUET A, HAIOUN C, JAIS JP, DEBARD AL, SALLES $G$, et al. Peripheral blood natural killer cell count is associated with clinical outcome in patients with aaIPI 2-3 diffuse large B-cell lymphoma. Ann Oncol. 2007; 18: 1209-1215. http:// dx.doi.org/10.1093/annonc/mdm110

[29] ADVANI RH, CHEN H, HABERMANN TM, MORRISON VA, WELLER EA, et al. Comparison of conventional prognostic indices in patients older than 60 years with diffuse large B-cell lymphoma treated with R-CHOP in the US Intergroup Study (ECOG 4494, CALGB 9793): consideration of age greater than 70 years in an elderly prognostic index (E-IPI). Br J Haematol. 2010; 151: 143-51. http://dx.doi.org/10.1111/ j.1365-2141.2010.08331.x

[30] KATZ S, FORD AB, MOSCOWITZ RW, JACKSON BA, JAFFE MW. Studies of illness in the aged. The index of ADL: a standardized measure of biological and psychosocial function. JAMA. 1963; 185: 914-919. http://dx.doi.org/10.1001/ jama.1963.03060120024016

[31] LAWTON MP, BRODY EM. Assesment of older people: self-maintaining and instrumental activities of daily living. Gerontologist. 1969; 9: 179-186. http://dx.doi.org/10.1093/ geront/9.3 Part 1.179

[32] PAL SK, HURRIA A. Impact of age, sex, and comorbidity on cancer therapy and disease progression. J Clin Oncol. 2010; 28: 4086-4093. http://dx.doi.org/10.1200/JCO.2009.27.0579 
[33] JANSSEN-HEIJNEN ML, VAN SPRONSEN DJ, LEMMENS VE, HOUTERMAN S, VERHEIJ KD, et al. A populationbased study of severity of comorbidity among patients with non-Hodgkin's lymphoma: prognostic impact independent of International Prognostic Index. British Journal of Haematology. 2005; 129: 597-606. http://dx.doi.org/10.1111/ j.1365-2141.2005.05508.x

[34] WIERINGA A, BOSLOOPER K, HOOGENDOORN M, JOOSTEN P, BEERDEN T, et al. Comorbidity is an independent prognostic factor in patients with advanced-stage diffuse large B-cell lymphoma treated with R-CHOP: a populationbased cohort study. Br J Haematol. 2014; 165: 489-496. http:// dx.doi.org/10.1111/bjh.12765
[35] KOBAYASHI Y, MIURA K, HOJO A, HATTA Y, TANAKA $\mathrm{T}$, et al. Charlson Comorbidity Index is an independent prognostic factor among elderly patients with diffuse large B-cell lymphoma. J Cancer Res Clin Oncol. 2011; 137: 1079-1084. http://dx.doi.org/10.1007/s00432-010-0973-x

[36] BOSLOOPER K, KIBBELAAR R, STORM H, VEEGER NJ, HOVENGA S, et al. Treatment with rituximab, cyclophosphamide, doxorubicin, vincristine and prednisolone is beneficial but toxic in very elderly patients with diffuse large B-cell lymphoma: a population-based cohort study on treatment, toxicity and outcome. Leuk Lymphoma. 2014; 55: 526-532. http://dx.doi.org/10.3109/10428194.2013.81 $\underline{0737}$ 